\title{
Prenatal exposure to metals and neurodevelopment in infants at six months: Rio Birth Cohort Study of Environmental Exposure and Childhood Development (PIPA Project).
}

Monica Seefelder de Assis Araujo ( $\nabla$ monica.seefelder@nutricao.ufrj.br)

UFRJ: Universidade Federal do Rio de Janeiro https://orcid.org/0000-0002-6352-9943

Nataly Damasceno de figueiredo

UFRJ ME: Universidade Federal do Rio de Janeiro Maternidade Escola Jorge Fonte de Rezende Flho

UFRJ ME: Universidade Federal do Rio de Janeiro Maternidade Escola Joffre Amim Junior

UFRJ ME: Universidade Federal do Rio de Janeiro Maternidade Escola

Marlos Melo Martins

UFRJ ME: Universidade Federal do Rio de Janeiro Maternidade Escola

Santos Alves Vicentini Neto

FIOCRUZ: Fundacao Oswaldo Cruz

Lisia Maria Gobbo dos Santos

FIOCRUZ: Fundacao Oswaldo Cruz

Silvana do Couto Jaco

FIOCRUZ: Fundacao Oswaldo Cruz

Volney Magalhães Camara

UFRJ FM: Universidade Federal do Rio de Janeiro Faculdade de Medicina

Ronir Raggio Luiz

UFRJ: Universidade Federal do Rio de Janeiro

Arnaldo Prata Barbosa

UFRJ ME: Universidade Federal do Rio de Janeiro Maternidade Escola

Carmen Ildes Rodrigues Froes Asmus

UFRJ ME: Universidade Federal do Rio de Janeiro Maternidade Escola

\section{Research Article}

Keywords: Environmental child health, Environmental exposure, Heavy metals, Neurodevelopment, Umbilical cord blood 
Posted Date: July 23rd, 2021

DOI: https://doi.org/10.21203/rs.3.rs-734023/v1

License: (c) (i) This work is licensed under a Creative Commons Attribution 4.0 International License. Read Full License 


\section{Abstract}

The PIPA Project is a prospective birth cohort study based in Rio de Janeiro, Brazil, whose pilot study was carried out between October 2017 and August 2018. Arsenic (As), cadmium (Cd), lead (Pb), and mercury $(\mathrm{Hg})$ concentrations were determined in maternal $(n=49)$ and umbilical cord blood $(n=46)$. The Denver Developmental Screening Test II (DDST-II) was applied in 50 six-month-old infants. Metals were detected in $100 \%$ of the mother and newborn samples above the limits of detection. Maternal blood lead concentrations were higher in premature newborns (GM: $5.72 \mu \mathrm{g} / \mathrm{dL} ; \mathrm{p}=0.05)$. One-third of the infants $(17-33 \%)$ exhibited at least one fail in the neurodevelopment evaluation (fail group). Maternal blood arsenic concentrations were significantly $(p=0.02)$ higher in the "fail group" (GM: $11.85 \mu \mathrm{g} / \mathrm{L})$ compared to infants who did not fail (not fail group) (GM: $8.46 \mu \mathrm{g} / \mathrm{L}$ ). Maternal and umbilical cord blood arsenic concentrations were higher in all Denver Test's domains (except personal/social) in the "fail group", albeit non-statistically significant. These findings indicate the need to further investigate the toxic effects of prenatal exposure to metals on infant neurodevelopment.

\section{Introduction}

Metals are significant environmental pollutants and may originate from natural sources or as a result of human activities (Jaishankar et al., 2014). The Agency for Toxic Substances and Disease Registry (ATSDR) lists arsenic (As), cadmium (Cd), lead (Pb) and mercury $(\mathrm{Hg})$ in the Priority Substance List, based on a combination of frequency, toxicity and potential for human exposure (ATSDR, 2017).

Chronic low-dose exposure to these metals may cause toxic human health effects (Morais et al., 2012). Environmental exposure to heavy metals can occur through inhalation (indoor and outdoor air pollution) or ingestion of contaminated food and water (Goyer, 1996, Tchounwou et al, 2012). Some metals, such as mercury and lead, are known neurotoxic elements (Schofield, 2017). Neurotoxic metals may represent a risk for child neurodevelopment during critical early life periods (Dórea, 2020). Fetal brain development during pregnancy, for example, is susceptible to the action of neurotoxic substances (Schofield, 2017), as the placental barrier is not completely impermeable to the passage of harmful substances, including heavy metals (Caserta et al, 2013). Several studies have reported an association between metal exposure during pregnancy and early childhood and impaired cognitive function in children (Lanphear et al., 2005; Bellinger, 2008; Jurewicz, Polanska and Hanke, 2013; Liu et al.,2014).

In Brazil, few studies have investigated metals in maternal and umbilical cord blood (Rosalem, 2004; Santos et al, 2007; Amaral et al., 2010; Rudge et al., 2011; de Assis Araujo et al, 2020). In one study carried out with 117 newborns in the city of Rio de Janeiro, Southeastern Brazil, de Assis Araujo et al. (2020) observed As, Cd, $\mathrm{Pb}$ and $\mathrm{Hg}$ concentrations above the limit of detection (LD) in all maternal and umbilical cord blood samples and Pb concentrations near $5 \mu \mathrm{g} / \mathrm{dL}$ in $25 \%$ of the investigated newborns (de Assis Araujo et al.; 2020). 
The Rio Birth Cohort Study on Environmental Exposure and Child Development (PIPA Project) is a prospective cohort study conducted at the Federal University of Rio de Janeiro Maternity School, in the city of Rio de Janeiro, southeastern Brazil, aiming at the investigation of the effects of environmental pollutants on maternal and child health. A pilot study (PIPA Pilot study) was carried out between September 2017 and August 2018, with 142 pregnant women enrolled in and 135 children born at the Federal University of Rio de Janeiro Maternity School (Asmus et al, 2020). This study investigates potential associations between metal concentrations in maternal and umbilical cord blood and newborn neurological development among the PIPA pilot study population.

\section{Material And Methods \\ 2.1 Study area}

The PIPA Pilot Study was carried out for 12 months, from September 2017 to August 2018, at the UFRJ Maternity School (UFRJ Maternity). The UFRJ Maternity is located in the South zone of the city of Rio de Janeiro and is a reference maternity hospital for the delivery of eight family health centers (CSFs) responsible for the prenatal care of populations living in low-income communities in this city zone. It is also a reference for the monitoring of high-risk pregnancies in the Rio de Janeiro public health system.

\subsection{Study population}

A total of 135 children were born at the UFRJ Maternity between October 2017 and February 2018 during the PIPA Pilot Study. Five dropouts occurred, so 130 newborns were eligible for follow-up visits. In this assessment, the study population comprises all children that returned for a follow-up visit in the sixth months, totaling 58 infants (44.6\%). The infants were evaluated using the Denver Developmental Screening Test II (DDST-II). Exclusion criteria comprised children admitted to the intensive care unit during the neonatal period, birth weight $<2.5 \mathrm{~kg}$, gestational age $<34$ weeks and mother drugs use during pregnancy. After these exclusions, the study population comprised a total of 50 (38.5\%) children (Fig. 1).

\subsection{Arsenic, cadmium, lead and mercury determinations}

Arsenic, $\mathrm{Cd}, \mathrm{Pb}$ and $\mathrm{Hg}$ in maternal blood samples collected during the third trimester of pregnancy and umbilical cord blood collected during delivery were analyzed employing the inductively coupled plasma mass spectrometry technique (ICP-MS), at the National Institute for Quality Control in Health (INCQS) laboratoty, at the Oswaldo Cruz Foundation (FIOCRUZ). The limits of quantification (LQ) for As, Cd, Pb and $\mathrm{Hg}$ were, respectively $0.01 \mu \mathrm{g} / \mathrm{L}, 0.006 \mu \mathrm{g} / \mathrm{L}, 0.05 \mu \mathrm{g} / \mathrm{L}$ and $0.02 \mu \mathrm{g} / \mathrm{L}$, while the limits of detection (LD) were $0.003 \mu \mathrm{g} / \mathrm{L} 0.002 \mu \mathrm{g} / \mathrm{L}, 0.015 \mu \mathrm{g} / \mathrm{L}$ and $0.007 \mu \mathrm{g} / \mathrm{L}$, respectively. The sample collection and analysis procedures have been previously described by Asmus et al (2020).

\subsection{Denver Development Screening Test II (DDST-II)}

Infant neurodevelopment was assessed using the Denver Developmental Screening Test II (DDST-II). The DDST-II is the 1992 revised version of the Denver Screening Test developed by Frankenburg and Dodds in 
1967 (Frankenburg, Dodds and Archer, 1992). The DDST-II used herein is the version translated into Portuguese. The Brazilian Society of Pediatrics recommends this test to monitor child development (Pinto et al, 2015). The DDST-II can be applied by health professionals directly to the child or through its parents or guardians. The purpose of this tool is to screen neuromotor development, evaluating children from zero to six years old regarding their ability to perform tasks organized in four neurodevelopmental domains: "Personal-Social", "Fine Adaptive Motor", "Gross Motor" and "Language". Each task is represented by a bar that indicates the age in which task compliance is performed by $25 \%, 50 \%, 75 \%$ and $90 \%$ of children. A score is given to each task evaluated, as follows: "pass, fail, refuse, no opportunity" (Frankenburg, 1996).

For all newborns, a follow-up appointment at sixth months was scheduled, when the DDST-II was applied for neurodevelopment assessment, in the presence of the mother by a specially trained examiner who was unaware of the child's developmental history and of the metal levels at the time of the test.

All "fail" and "refuse" scores were considered as "fail.", and "no opportunity" and "pass" scores were considered to "not fail."

\subsection{Statistical analyses}

A descriptive analysis of participants characteristics was performed. Frequency distributions for categorical variables and arithmetic mean and median for the continuous variables were calculated. The geometric means, 25th, 50th, 75th, 90th and 95th percentiles and the minimum and maximum values of the pollutant concentration levels were calculated for the maternal and umbilical cord blood samples.

Spearman's correlation or non-parametric comparisons (Mann-Whitney) or parametric (Student) tests were used to evaluate continuous variables and Chi-squared or Fisher tests were used for categorical variables. All data were analyzed using the SPSS v. 21 software.

\section{Results}

Arsenic, $\mathrm{Cd}, \mathrm{Pb}$, and $\mathrm{Hg}$ were above the $\mathrm{LQ}$ in all maternal blood and umbilical cord blood samples (Table 1). A significant positive correlation was observed between all metal concentrations in maternal and umbilical cord blood, as previously described by Figueiredo et al. (2020).

Mean mother age was 28.54 years old (SD \pm 7.07 ), with a mean per capita income of U\$ 257.00 (SD \pm 167.38) and median of 14 years of schooling; $71.4 \%$ of the mothers were non-white, $36.7 \%$ reported exposure to tobacco (personal and second-hand exposure) and $50.0 \%$ consumed alcohol during pregnancy. A statistically significant positive correlation between maternal age and cord blood concentrations were observed for $\mathrm{Hg}(r=0.34 ; 0.02)$ and $\mathrm{Pb}(r=0.29 ; 0.05)$. Non-white pregnant women presented higher geometric $\mathrm{Cd}$ means in maternal blood $(p=0.04)$ and cord blood $(p=0.08)$ compared to white women (Table 2). 
Mean birth weight was $3.3 \mathrm{~kg}$ (SD $\pm 0.5 \mathrm{~kg}$ ) and median gestational age was 39 weeks (range: 36 41 weeks), $62.0 \%(n=31)$ of all infants were male, $11.1 \%(n=5)$ were small for gestational age (SGA) and $6.0 \%(n=3)$, premature (IG 34 - 37 weeks). The geometric $\mathrm{Pb}$ mean in maternal blood (5.72 $\mu \mathrm{g} / \mathrm{dL} ; \mathrm{p}=$ $0.05)$ and in cord blood $(7.23 \mu \mathrm{g} / \mathrm{dL} ; \mathrm{p}=0.16)$ was higher in premature babies. An inverse correlation trend was observed between gestational age and Cd concentrations in maternal blood $(-0.25 ; p=0.08)$ and in umbilical cord blood $(-0.21 ; p=0.16)$ (Table 3$)$.

In the sixth month follow-up visit, 50 eligible children were evaluated with regard to the four neurodevelopmental Denver Test's domains. Most (33-66.0\%) did not fail in any domain ("not fail" group) and 17 (33.0\%) children failed in one or more domains ("fail" group). No differences were observed concerning maternal sociodemographic characteristics and birth characteristics between the "fail" and "not fail" groups (Table 4).

Comparisons between the metal concentrations geometric means in maternal blood and cord blood between the "fail" and "not fail" groups in the sixth month are displayed in Table 5. The geometric means for maternal blood As were significantly higher in the "fail group" compared to the "not fail group" $(p=0.02)$. The maternal and cord blood As concentrations were higher also in the "fail group" for the fine adaptative motor $(p=0.27)$, language $(p=0.36)$, and gross motor $(p=0.07)$ Denver Test's domains, (Table 6), albeit non-significantly. No significant results were observed for the other metals between the "fail" and "not fail" groups and each DDST-II domain.

\section{Discussion}

To the best of our knowledge, this study is the first in the city of Rio de Janeiro to investigate prenatal exposure to $\mathrm{As}, \mathrm{Cd}, \mathrm{Pb}$ and $\mathrm{Hg}$ and the neurodevelopment of children up to 6 months of age.

Maternal and umbilical cord blood geometric means for As were higher in the "fail" group for DDST-II in the six month, statistically significant for maternal blood. Some studies have investigated the effect of prenatal exposure to As on neurological infant development. Liang et al. (2020), in a prospective Chinese birth cohort study (Ma'anshan Birth Cohort-MABC) on 2315 six-month-old infants, observed associations between umbilical cord serum As concentration (median $=1.89 \mu \mathrm{g} / \mathrm{L}$ ) and suspected developmental delay in the personal-social domain (Liang et al, 2020). Wang et al. (2018), in a cross-sectional study carried out in Shanghai $(n=892)$, observed that newborns with a low neonatal behavioral neurological assessment (NBNA) score exhibited higher concentrations (median, interquartile range) of umbilical cord As $(3.93,1.27-8.21 \mu \mathrm{g} / \mathrm{L})$ than those with a high NBNA score $(0.61,0.23-1.50 \mu \mathrm{g} / \mathrm{L})$. Tolins, Ruchirawat, \& Landrigan, (2014), concluded in a review study that intrauterine exposure may be associated with neurodevelopment deficits, even at exposure levels below current safety guidelines $(10 \mu \mathrm{g} / \mathrm{L}$ in drinking water), with manifestations detected only later in life. Those authors also observed that certain factors, such as sex, concomitant exposures and exposure time, modify developmental As neurotoxicity.

No associations between fails in the neurodevelopment domains and maternal or cord blood $\mathrm{Cd}, \mathrm{Pb}$, and $\mathrm{Hg}$ concentrations in our study population were observed. Nevertheless, in a systematic review study, 
Asmus et al (2016) reported a body of studies demonstrating associations between high child exposure to $\mathrm{Hg}$ in the Brazilian Amazon and poor neurobehavioral assessment results. Marques et al $(2007,2009)$, evaluated the neuromotor development of 82 six-month-old children, in the Brazilian Amazon and observed an inverse and significant correlation between hair $\mathrm{Hg}$ contents and neurodevelopment delay $(r$ $=-0.333 ; p=0.002$ ) (Marques et al, 2007; Marques et al, 2009; Asmus et al, 2016).

Birth conditions and nutritional status are known to interfere in child neurodevelopment (Halpern et al., 1996; Costa et al., 2015; Hirvonen et al., 2017; Allotey et al., 2018). Halpern et al. (1996), in a study carried out in the city of Pelotas, southern Brazil, with 1362 one-year-old children, observed the occurrence of neurodevelopmental failures through the application of the DDST-II, inversely associated with birth weight. Higher birth weights were observed herein in the "not fail" group, although not statistically significant.

We report herein a positive correlation between maternal age and $\mathrm{Pb}(0.29 ; \mathrm{p}=0.05)$ and $\mathrm{Hg}(0.34 ; \mathrm{p}=$ 0.02 ) levels in umbilical cord blood (Table 2). Other studies have also reported that maternal age is associated with higher $\mathrm{Pb}$ and $\mathrm{Hg}$ levels in umbilical cord blood (Bjerregaar \& Hansen, 2000; Arbuckle et al, 2016; Bocca et al, 2020; Hadavifar et al, 2020). This may be due to the accumulation of these metals in the body (Bocca et al, 2019). The higher $\mathrm{Hg}$ and $\mathrm{Pb}$ concentrations in umbilical cord compared to maternal blood can be attributed to increased glomerular filtration rates during pregnancy, resulting in higher renal elimination (Selevan, Kimmel \& Mendola, 2000). A significant positive correlation was observed between $\mathrm{As}, \mathrm{Cd}, \mathrm{Pb}$, and $\mathrm{Hg}$ concentrations in maternal and umbilical cord blood, as previously described by Figueiredo et al (2020).

The maternal and cord blood geometric means for $\mathrm{Cd}$ were higher in the non-white ethnic group, significant only for maternal blood. Some studies suggest that higher biological Cd levels may be associated to a more socioeconomically vulnerable population, including lower socioeconomic favored ethnicities (Lewin et al, 2017; Bulka et al 2019), as is the case of the non-white population in Brazil.

Associations between gestational age and metal concentrations has been investigated in many studies (Ettinger \& Wengrovitz, 2010; Kumar et al, 2017; Ashrap et al 2020). In the present assessment, maternal blood $\mathrm{Pb}$ concentrations were significantly higher in preterm children (gestational age $>34$ weeks and $<$ 37 weeks). No associations were observed between maternal or cord blood As concentrations and gestational age.

No significant associations were observed between mother age, income, education, ethnicity or tobacco or alcohol use and the "fail" and "not fail" groups. The differences between the results reported herein and other studies may be due to sample size, metal concentrations, the type of test used to assess neurodevelopment and the influence of sociodemographic factors and lifestyle (Bellinger, 2009). The long-term development of the investigated children may alter the results, as other areas of child development will be better analyzed with a longer observation time. 
A limitation of this study comprises the individual analysis of each metal without considering their potential interactions and the small number of participants. Despite this, these findings provide information on environmental prenatal exposure to metals and potentially adverse neurodevelopment effects on newborns, encompassing sociodemographic and lifestyle data.

\section{Conclusion}

This study provides evidence of associations between As concentrations in maternal blood and fails in infant DDST-II. Continuous monitoring of neurotoxic substance concentrations in women at reproductive age is paramount to establish preventive measures to eliminate or minimize the risk of fetal exposure during pregnancy. Longer-term development studies may reveal other associations. Future investigations should aim to demonstrate the possible neurodevelopment effects of prenatal exposure to environmental pollutants on child health and identify potential exposure sources.

\section{Declarations}

Acknowledgements The authors would like to acknowledge the UFRJ Maternity School team for the broad support of the PIPA project and the study participants for their contributions.

Author Contributions All the authors participated in the conception and design, or analysis and interpretation of the data, drafting the article or revising it critically for important intellectual content. All the authors approved the final version. This manuscript is original research and has not been submitted to, nor is under review at, another journal or other publishing venue.

Funding Funding was received from the Brazilian Government: National Council for Scientific and Technological Development (Grant No. 409275/2018-2), Science and Technology Department (Grant No.404168/2019-1), Surveillance Health Secretary (Grant No. 733663/19- 002), and Ministry of Health and the Carlos Chagas Filho Foundation for Supporting Research in the State of Rio de Janeiro (Grant No. E-26/010.001894/2019).

Conflict of interest The authors do not have any competing or conflicts of interest.

Ethical Approval This research involved human participants and all procedures were approved by the Federal University of Rio de Janeiro (UFRJ) Maternity School Ethics Committee (reference number: 2.092.440) and the Fiocruz Foundation Ethics Committee (reference number: 2.121.397).

Informed Consent All participants signed an informed consent before any procedure was performed.

Consent for Publication All the authors agree with the publication of this manuscript.

Data availability The datasets generated during and/or analysed during the current study are available from the corresponding author on reasonable request. 


\section{References}

1. Allotey J, Zamora J, Cheong-See F, Kalidindi M, Arroyo-Manzano D, Asztalos E, ... Thangaratinam S (2018) Cognitive, motor, behavioural and academic performances of children born preterm: a metaanalysis and systematic review involving 64061 children. BJOG: An International Journal of Obstetrics Gynaecology 125(1):16-25. https://doi.org/10.1111/1471-0528.14832

2. Amaral JH, Rezende VB, Quintana SM, Gerlach RF, Barbosa Jr F, Tanus - Santos JE (2010) 'The relationship between blood and serum lead levels in peripartum women and their respective umbilical cords', Basic \& clinical pharmacology \& toxicology, 107 (6), pp. 971-975. https://doi.org/10.1111/j.1742-7843.2010.00616.x

3. Arbuckle TE, Liang CL, Morisset AS, Fisher M, Weiler H, Cirtiu CM, ... MIREC Study Group (2016) Maternal and fetal exposure to cadmium, lead, manganese and mercury: the MIREC study. Chemosphere, 163, 270-282. https://doi.org/10.1016/j.chemosphere.2016.08.023

4. Ashrap P, Watkins DJ, Mukherjee B, Boss J, Richards MJ, Rosario Z, ... Meeker JD (2020) Maternal blood metal and metalloid concentrations in association with birth outcomes in Northern Puerto Rico. Environment international 138:105606. https://doi.org/10.1016/j.envint.2020.105606

5. Asmus CIF, Camara VM, Landrigan PJ, Claudio L (2016) A systematic review of children's environmental health in Brazil. Annals of global health 82(1):132-148. https://doi.org/10.1016/j.aogh.2016.02.007

6. Asmus CIRF, Barbosa AP, Meyer A, Damasceno N, Rosa ACS, Medronho R, ... de Magalhães Câmara V (2020) Rio Birth Cohort Study on Environmental Exposure and Childhood Development-PIPA Project. Annals of global health, 86(1). https://dx.doi.org/10.5334\%2Faogh.2709. PMID: 32566487

7. AGENCY FOR TOXIC SUBSTANCES AND DISEASE REGISTRY. ATSDR's Substance Priority List (2019) https://www.atsdr.cdc.gov/spl/\#2019spl. (accessed 04 May 2021)

8. Bellinger DC (2008) 'Very low lead exposures and children's neurodevelopment', Current opinion in pediatrics, 20 (2), pp. 172-177. https://doi.org/10.1097/mop.0b013e3282f4f97b. PMID: 18332714

9. Bellinger DC (2009) Interpreting epidemiologic studies of developmental neurotoxicity: conceptual and analytic issues. Neurotoxicol Teratol 31(5):267-274. https://doi.org/10.1016/j.ntt.2009.06.006

10. Bjerregaard $P$, Hansen JC (2000) Organochlorines and heavy metals in pregnant women from the Disko Bay area in Greenland. Sci Total Environ 245(1-3):195-202. https://doi.org/10.1016/S00489697(99)00444-1

11. Bocca B, Ruggieri F, Pino A, Rovira J, Calamandrei G, Martínez M, ... Schuhmacher M (2019) Human biomonitoring to evaluate exposure to toxic and essential trace elements during pregnancy. Part $\mathrm{A}$. concentrations in maternal blood, urine and cord blood. Environmental research 177:108599. https://doi.org/10.1016/j.envres.2019.108599

12. Bocca B, Ruggieri F, Pino A, Rovira J, Calamandrei G, Mirabella F, ... Schuhmacher M (2020) Human biomonitoring to evaluate exposure to toxic and essential trace elements during pregnancy. Part $\mathrm{B}$ : 
Predictors of exposure. Environmental research 182:109108.

https://doi.org/10.1016/j.envres.2019.109108

13. Bulka CM, Bommarito PA, Fry RC (2019) Predictors of toxic metal exposures among US women of reproductive age. J Expo Sci Environ Epidemiol 29(5):597-612. https://doi.org/10.1038/s41370-0190152-3

14. Caserta D, Graziano A, Monte GL, Bordi G, Moscarini M (2013) Heavy metals and placental fetalmaternal barrier: a mini-review on the major concerns. Eur Rev Med Pharmacol Sci 17(16):21982206. PMID: 23893187

15. Costa EF, Cavalcante LIC, Dell'Aglio DD (2015) Language development profile of children in Belem, according to Denver developmental screening test. Revista CEFAC 17(4):1090-1102. https://doi.org/10.1590/1982-0216201517418514

16. de Assis Araujo MS, Figueiredo ND, Camara VM, Asmus CIRF (2020) Maternal-child exposure to metals during pregnancy in Rio de Janeiro city, Brazil: The Rio Birth Cohort Study of Environmental Exposure and Childhood Development (PIPA project). Environ Res 183:109155. https://doi.org/10.1016/j.envres.2020.109155

17. Dórea JG (2020) Exposure to environmental neurotoxic substances and neurodevelopment in children from Latin America and the Caribbean. Environmental research, 110199. https://doi.org/10.1016/j.envres.2020.110199

18. Figueiredo ND, Araújo MS, Luiz RR, de Magalhaes Câmara V, do Couto Jacob S, Dos Santos LM, Vicentini SA, Asmus Cl (2020 Nov;27(32):40210-8) Metal mixtures in pregnant women and umbilical cord blood at urban populations-Rio de Janeiro, Brazil. Environmental Science and Pollution Research. https://doi.org/10.1007/s11356-020-10021-w

19. Ettinger AS, Wengrovitz AM (2010) Guidelines for the identification and management of lead exposure in pregnant and lactating women. https://stacks.cdc.gov/view/cdc/11854 (acessed 31 may 2021)

20. Frankenburg WK, Dodds J, Archer P, Shapiro H, Bresnick B (1992) The Denver II: a major revision and restandardization of the Denver Developmental Screening Test. Pediatrics 89(1):91-97. PMID: 1370185

21. Frankenburg WK (1996) Denver II: technical manual. Denver Developmental Materials, Incorporated

22. Liu J, Goyer RA, Walkes MP (2008) Toxic effects of metals. In: Klaassen CD(ed) Casarett and Doull's toxicology: the basic science of poisons. McGraw-Hill Companies, Inc., pp 931-979.

DOI:10.1036/0071470514

23. Hadavifar M, Rastakhiz M, Souvizi B, Miri HH, Akrami R (2020) Biomonitoring of maternal and fetal exposure to mercury in Sabzevar and its affecting risk factors. J Hazard Mater 388:121781. https://doi.org/10.1016/j.jhazmat.2019.121781

24. Halpern R, Barros FC, Horta BL, Victora CG (1996) Desenvolvimento neuropsicomotor aos 12 meses de idade em uma coorte de base populacional no Sul do Brasil: diferenciais conforme peso ao 
nascer e renda familiar. Cadernos de saúde pública 12:S73-S78. https://doi.org/10.1590/S0102$311 \times 1996000500011$

25. Hirvonen M, Ojala R, Korhonen P, Haataja P, Eriksson K, Rantanen K, ... Tammela O (2017) Intellectual disability in children aged less than seven years born moderately and late preterm compared with very preterm and term-born children-a nationwide birth cohort study. J Intellect Disabil Res 61(11):1034-1054. https://doi.org/10.1111/jir.12394

26. Jaishankar M, Tseten T, Anbalagan N, Mathew BB, Beeregowda KN (2014) 'Toxicity, mechanism and health effects of some heavy metals', Interdisciplinary toxicology, 7 (2), pp. 60-72. https://dx.doi.org/10.2478\%2Fintox-2014-0009. PMID: 26109881

27. Jurewicz J, Polanska K, Hanke W (2013) 'Chemical exposure early in life and the neurodevelopment of children - an overview of current epidemiological evidence', Annals of agricultural and environmental medicine, 20 (3). PMID: 24069851

28. Kumar S, Sharma S, Thaker R (2017) Occupational, Environmental, and Lifestyle Factors and their Contribution to Preterm Birth - An Overview. Indian journal of occupational and environmental medicine, 21(1), 9-17. https://doi.org/10.4103/ijoem.IJOEM_155_16. PMID: 29391742

29. Lanphear BP, Hornung R, Khoury J, Yolton K, Baghurst P, Bellinger DC, Canfield RL, Dietrich KN, Bornschein R, Greene T (2005) 'Low -level environmental lead exposure and children's intellectual function: an international pooled analysis'. Environmental health perspectives 113(7):894. https://doi.org/10.1289/ehp.7688

30. Lewin A, Arbuckle TE, Fisher M, Liang CL, Marro L, Davis K, ... Fraser WD (2017) Univariate predictors of maternal concentrations of environmental chemicals: the MIREC study. Int J Hyg Environ Health 220(2):77-85. https://doi.org/10.1016/j.ijheh.2017.01.001

31. Liang C, Wu X, Huang K, Yan S, Li Z, Xia X, ... Tao F (2020) Domain-and sex-specific effects of prenatal exposure to low levels of arsenic on children's development at 6 months of age: Findings from the Ma'anshan birth cohort study in China. Environment international 135:105112. https://doi.org/10.1016/j.envint.2019.105112

32. Liu JA, Chen Y, Gao D, Jing J, Hu Q (2014) Prenatal and postnatal lead exposure and cognitive development of infants followed over the first three years of life: a prospective birth study in the Pearl River Delta region, China. Neurotoxicology 44:326-334. https://doi.org/10.1016/j.neuro.2014.07.001

33. Marques RC, Dórea JG, Bastos WR, de Freitas Rebelo M, de Freitas Fonseca M, Malm O (2007) Maternal mercury exposure and neuro-motor development in breastfed infants from Porto Velho (Amazon), Brazil. international Journal of Hygiene environmental Health 210(1):51-60. https://doi.org/10.1016/j.jheh.2006.08.001

34. Marques RC, Dórea JG, Bernardi JV, Bastos WR, Malm O (2009) Prenatal and postnatal mercury exposure, breastfeeding and neurodevelopment during the first 5 years. Cognitive and behavioral neurology: official journal of the Society for Behavioral and Cognitive Neurology, 22(2), 134-141. https://doi.org/10.1097/WNN.0b013e3181a72248. PMID: 19506431 
35. Morais S, Costa FG, Pereira MDL (2012) Heavy metals and human health in: Oosthuizen, J. (eds.), Environmental health-emerging issues and practice. Intechopen.com. pp. 227-245. DOI: 10.5772/1519. Print ISBN: 978-953-307-854-0

36. Pinto FCDA, Isotani SM, Sabatés AL, Perissinoto J (2015) Denver Il: proposed behaviors compared to those of children from São Paulo Revista CEFAC, 17(4), 1262-1269. https://doi.org/10.1590/19820216201517418214. ISSN 1982 - 0216

37. Rosalem A (2004) 'Association between environmental factors of exposure to lead and lead in spontaneous abortion'. Universidade Estadual de Campinas, Campinas. http://repositorio.unicamp.br/jspui/handle/REPOSIP/313321

38. Rudge CVC, Calderon IMP, Rudge MVC, Volpato G, Silva JLP, Duarte G, Neto CM, Sass N, Mattar R, Röllin HB (2011) 'Toxic and essential elements in blood from delivering women in selected areas of São Paulo State, Brazil '. Journal of Environmental

39. Monitoring, 13 (3), pp. 563-571. https://doi.org/10.1039/COEM00570C

40. Santos EO, Jesus IMD, Câmara VDM, Brabo EDS, Jesus MID, Fayal KF, Asmus CIRF (2007) Correlation between blood mercury levels in mothers and newborns in Itaituba, Pará State, Brazil. Cadernos de saúde pública, 23, S622-S629. https://doi.org/10.1590/S0102-311X2007001600022

41. Schofield K (2017) The metal neurotoxins: an important role in current human neural epidemics? Int J Environ Res Public Health 14(12):1511. https://doi.org/10.3390/ijerph14121511

42. Selevan SG, Kimmel CA, Mendola $P$ (2000) Identifying critical windows of exposure for children's health. Environmental health perspectives 108(suppl 3):451-455. https://doi.org/10.1289/ehp.00108s3451

43. Tchounwou PB, Yedjou CG, Patlolla AK, Sutton DJ (2012) Heavy Metal Toxicity and the Environment. In: Luch A (ed) Molecular, Clinical and Environmental Toxicology. Experientia Supplementum, vol 101. Springer, Basel. https://doi.org/10.1007/978-3-7643-8340-4_6

44. Tolins M, Ruchirawat M, Landrigan P (2014) The developmental neurotoxicity of arsenic: cognitive and behavioral consequences of early life exposure. Annals of global health 80(4):303-314. https://doi.org/10.1016/j.aogh.2014.09.005

45. Wang B, Liu J, Liu B, Liu X, Yu X (2018) Prenatal exposure to arsenic and neurobehavioral development of newborns in China. Environment international 121:421-427. https://doi.org/10.1016/j.envint.2018.09.031

\section{Tables}

Due to technical limitations, Table 1,2,3,4, 5 and 6 are only available as a download in the Supplemental Files section.

\section{Figures}


Children born at the UFRJ Maternity: 135

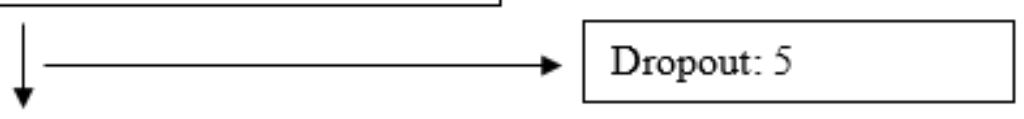

Newborns eligible for follow- up: 130

Children that returned in the sixth month: 58

\begin{tabular}{|l|l|}
$\longrightarrow$ & $\begin{array}{l}\text { Excluded children: Admission at a } \\
\text { neonatal intensive care unit, birth wight } \\
<2.5 \mathrm{~kg} \text {, gestational age }<34 \text { weeks or } \\
\text { drug use during pregnancy: } 8\end{array}$ \\
\hline Study population: 50
\end{tabular}

Figure 1

Selection process of the study population.

\section{Supplementary Files}

This is a list of supplementary files associated with this preprint. Click to download.

- MonicaSeefelderTable.docx 